\title{
Dietary fructose and risk of metabolic syndrome in adults: Tehran Lipid and Glucose study
}

\author{
Firoozeh Hosseini-Esfahani ${ }^{1}$, Zahra Bahadoran ${ }^{1}$, Parvin Mirmiran ${ }^{2 *}$, Somayeh Hosseinpour-Niazi ${ }^{1}$, \\ Farhad Hosseinpanah ${ }^{1}$ and Fereidoun Azizi ${ }^{3}$
}

\begin{abstract}
Background: Studies have shown that the excessive fructose intake may induce adverse metabolic effects. There is no direct evidence from epidemiological studies to clarify the association between usual amounts of fructose intake and the metabolic syndrome.

Objective: The aim this study was to determine the association of fructose intake and prevalence of metabolic syndrome (MetS) and its components in Tehranian adults.

Methods: This cross-sectional population based study was conducted on 2537 subjects (45\% men) aged 19-70 y, participants of the Tehran Lipid and Glucose Study (2006-2008). Dietary data were collected using a validated 168 item semi-quantitative food frequency questionnaire. Dietary fructose intake was calculated by sum of natural fructose (NF) in fruits and vegetables and added fructose (AF) in commercial foods. MetS was defined according to the modified NCEP ATP III for Iranian adults.

Results: The mean ages of men and women were $40.5 \pm 13.6$ and $38.6 \pm 12.8$ years, respectively. Mean total dietary fructose intakes were $46.5 \pm 24.5$ (NF: $19.6 \pm 10.7$ and AF: $26.9 \pm 13.9$ ) and $37.3 \pm 24.2$ g/d (NF: $18.6 \pm 10.5$ and AF: $18.7 \pm 13.6$ ) in men and women, respectively. Compared with those in the lowest quartile of fructose intakes, men and women in the highest quartile, respectively, had $33 \%(95 \% \mathrm{Cl}, 1.15-1.47)$ and $20 \%$ (95\% Cl, 1.091.27) higher risk of the metabolic syndrome; $39 \%(\mathrm{Cl}, 1.16-1.63)$ and $20 \%(\mathrm{Cl}, 1.07-1.27)$ higher risk of abdominal obesity; $11 \%(\mathrm{Cl}, 1.02-1.17)$ and $9 \%(\mathrm{Cl}, 1.02-1.14)$ higher risk of hypertension; and $9 \%(\mathrm{Cl}, 1-1.15)$ and $9 \%(1.04-1.12)$ higher risk of impaired fasting glucose.
\end{abstract}

Conclusion: Higher consumption of dietary fructose may have adverse metabolic effects.

Keywords: Dietary fructose, Metabolic syndrome, Tehran Lipid and Glucose Study

\section{Introduction}

Fructose is the sweetest tasting carbohydrate, found in many fruits and vegetables. In the past, dietary intake of fructose was used to be 16-20 grams per day, mainly from fresh fruits and vegetables. But in the last three decades, increased consumption of industrialized foods such as soft drinks, fruit juices, bakery products, canned fruits, jams, jellies and cookies, containing added sugars (sucrose, high fructose corn syrup, honey, molasses, and other syrups)

\footnotetext{
* Correspondence: mirmiran@endocrine.ac.ir

${ }^{2}$ Department of Clinical Nutrition and Dietetics, Faculty of Nutrition Sciences and Food Technology, National Nutrition and Food Technology Research Institute, Shahid Beheshti University of Medical Sciences. No 46 Arghavan-egharbi St, Farahzadi Blv, Shahrak-e-Ghods. Tehran, 19395-4741, Iran Full list of author information is available at the end of the article
}

has resulted in a significant increase in fructose intakes of 85-100 grams per day [1,2]. Recent data suggest parallel increasing trends in fructose intake and the increase in obesity and type 2 diabetes in the last 35 years $[3,4]$. Reports confirmed by animal and human clinical studies, indicating that the excessive fructose intakes induce adverse metabolic effects [5-10]; however there is no direct evidence from epidemiological studies to clarify the association between current amounts of dietary fructose intake and the metabolic syndrome components. Metabolic syndrome (MetS), a worldwide epidemic health problem, is characterized by central obesity, hypertension, insulin resistance, and lipid profiles abnormalities [11]. The prevalence of MetS in Iranian adults is reported to be one of the highest worldwide, with a rate of $33.7 \%[12,13]$.

\section{Biomed Central}


Considering the lack of data on dietary fructose intake in Iranian adults, the aim of this cross sectional study was to assess dietary intakes of fructose and to investigate the association between fructose intake and prevalence of MetS risk factors, in a sample selected from the Tehran Lipid and Glucose Study.

\section{Methods}

\section{Participants}

Data were obtained from subjects of the Tehran Lipid and Glucose Study (TLGS) between 2006-2008. Details of the Tehran Lipid and Glucose Study have been reported elsewhere $[14,15]$. Briefly, TLGS is a community-based prospective study conducted to investigate and prevent noncommunicable diseases, in a representative sample of residents, aged $\geq 3 \mathrm{y}$, from district 13 of Tehran, the capital of Iran. The first phase of the TLGS began in March 1999 and data collection, at three-year intervals, is ongoing [15]. From 12523 subjects, aged $\geq 3$ years, in 2006-2008, 4920 were randomly selected for dietary assessment, based on age and sex categorization, and 3462 (70 percent) completed the dietary assessment [16]. Of these, 2799 men and women aged 19-70 y, were recruited for this study. Subjects with under- or over reporting of dietary intakes (less than $800 \mathrm{kcal} / \mathrm{d}$ or more than $4200 \mathrm{kcal} / \mathrm{d}$, respectively) were excluded. Finally, the data of 2537 adults (1141men and 1396 women) were analyzed.

Dietary intake assessment and fructose intake estimation Dietary data were collected by using a validated semiquantitative food frequency questionnaire (FFQ) with 168 food items, based on consumption frequency for each food item during the past year, on a daily, weekly or monthly basis [17]. Since the Iranian Food composition Table (FCT), with limited data on nutrient content of raw foods and beverages, is incomplete, the U.S Department of Agriculture (USDA) FCT was used to calculate energy and nutrient intakes [18]. However the Iranian FCT was used for some national foods that are not listed in the USDA FCT [19]. Dietary intakes of naturally-occurring fructose from fructose-containing food such as fruits, vegetables, honey, etc, were defined as "natural fructose (NF)" and were calculated using the USDA FCT. Dietary simple carbohydrates was defined as total intakes of disaccharides (sucrose, galactose, lactose), monosaccharides (fructose, glucose, maltose), and the content of added sugar in industrialized foods. Intakes of fructose from industrialized foods and beverages containing beet or cane sugar/ molasses, corn sweeteners and invert syrup were defined as "added fructose (AF)". Since there are no databases for added sugar content of Iranian food products, the USDA database for added sugar was used to identify the added sugar contents of food items [20,21]. The most commonly added sugar in Iranian food products is sucrose, while other sweeteners such as corn syrup are not commonly employed. Hence $50 \%$ of added sugar in food products was considered as fructose. Eventually the intakes of total fructose were calculated by summing up natural fructose and added fructose consumed.

\section{Clinical and biological measurements}

Trained interviewers collected information using a pretested questionnaire [14]. Weight was measured to the nearest $100 \mathrm{~g}$ with digital scales, while the subjects were minimally clothed without shoes. Height was measured to the nearest $0.5 \mathrm{~cm}$, in a standing position without shoes, using a tape meter. Waist circumference was measured to the nearest $0.1 \mathrm{~cm}$, at the umbilical level and that of the hip, at the maximum level, over light clothing, using an unstretched tape meter, without any pressure to the body. Body mass index was calculated as weight $(\mathrm{kg})$ divided by square of the height $\left(\mathrm{m}^{2}\right)$. For blood pressure measurements, after a 15-minute rest in the sitting position, two measurements of blood pressure were taken, on the right arm, using a standardized mercury sphygmomanometer; the mean of the two measurements was considered as the participant's blood pressure. Fasting blood samples were taken after $12-14$ h, from all study participants. Fasting plasma glucose was measured by the enzymatic colorimetric method using glucose oxidase. Triglyceride levels were measured by enzymatic colorimetric analysis with glycerol phosphate oxidase. High-density lipoprotein cholesterol (HDL-C) was measured after precipitation of the apolipoprotein B containing lipoproteins with phosphotungistic acid. Analyses were performed using Pars Azmon kits (Pars Azmon Inc., Tehran, Iran) and a Selectra 2 auto-analyzer (Vital Scientific, Spankeren, Netherlands). Inter- and intra assay coefficient of variation of all assays were $<5 \%$ [14].

\section{Metabolic syndrome definition}

Metabolic syndrome was defined according to the diagnostic criteria proposed by NCEP ATP III, and new cutoff points of waist circumference for Iranian adults; it was characterized as having at least 3 of the metabolic abnormalities: 1) Fasting plasma glucose $\geq 100 \mathrm{mg} / \mathrm{dL}$ (5.6 mmol/ L) or drug treatment of hyperglycemia, 2) serum triglycerides $\geq 150 \mathrm{mg} / \mathrm{dL}(1.69 \mathrm{mmol} / \mathrm{L})$ or drug treatment, 3) serum HDL-cholesterol $<40 \mathrm{mg} / \mathrm{dL}(1.04 \mathrm{mmol} / \mathrm{L})$ for men, and $<50 \mathrm{mg} / \mathrm{dL}(1.29 \mathrm{mmol} / \mathrm{L})$ for women or drug treatment, 4) blood pressure $\geq 130 / 85 \mathrm{mmHg}$ or drug treatment for hypertension, and 5) waist circumference $\geq 95 \mathrm{~cm}$ for both sexes [22,23].

\section{Statistical analysis}

Statistical analysis was performed using SPSS (Version 16.0; Chicago, IL), with $P$ values $<0.05$ being considered significant. Dietary intakes of fructose were adjusted for 
energy intakes: [(fructose intake $(\mathrm{g} / \mathrm{d}) \times 1000 /$ energy intake $(\mathrm{kcal} / \mathrm{d})$ ]. Total dietary fructose was assigned as quartile intakes for men and women, based on their $25^{\text {th }}-50^{\text {th }}-75^{\text {th }}$ percentile values. Total dietary fructose intakes $(\mathrm{g} / 1000 \mathrm{kcal} / \mathrm{d})$ in the $1^{\text {st }}, 2^{\text {nd }}, 3^{\text {rd }}$ and $4^{\text {th }}$ quartiles were $\leq 13.3,13.4-17.5,17.6-23.7$, and $>23.7$ in men, and $\leq 10.3,10.4-15.2,15.3-20.8$, and $>20.8$ in women. Differences in general characteristics of participants across quartiles of fructose intakes were compared using one-way analysis of variance or the Chi-square test. Age adjusted means for dietary intakes across quartiles of fructose, were determined by using the general linear model. Means of metabolic syndrome features were compared across quartiles of fructose intake by using general linear model with adjustment for age (categorized, 19-30, 31-40, 41-50, 51-60, 61-70; groups 1 to 5), physical activity (continuous), energy intake (kcal/ d), and smoking (yes or no). The associations between total dietary fructose and metabolic syndrome risk factors, as continuous variables, were determined by using multivariate linear regression model with adjustment for age (categorized), BMI (except for waist circumference and MetS), physical activity (in MET-h/wk), smoking (yes or no), energy intake ( $\mathrm{kcal} / \mathrm{d}$ ), percentage of energy from fat, carbohydrate and simple carbohydrate (except fructose), total fiber intake (g/d), and also adjustment for current estrogen use (yes or no) and menopausal status (yes or no) in women. Also, the odds ratio of MetS and its component in each quartiles of total fructose intake was determined by using multivariable logistic regression model with adjustment for the abovementioned confounders. Since, the odds ratio, which was estimated from logistic regression models in cross sectional studies, is not a valid estimation in binary outcome variables with a high prevalence $(>10 \%)$, the adjusted odds ratios were corrected by the formula suggested by Zhang and $\mathrm{Yu}$, for better estimation of the association $[24,25]$. To assess the overall trends of odds ratios across increasing quartiles of total fructose intake, the median fructose intake of each quartile was used as a continuous variable in logistic regression models [26].

\section{Results}

In this study, $45 \%$ and $55 \%$ of participants were men and women, with mean ages of $40.5 \pm 13.6$ and $38.6 \pm 12.8$ years, respectively. Mean dietary intakes of total fructose were $46.5 \pm 24.5 \mathrm{~g} / \mathrm{d}$ (NF: $19.5 \pm 10.7$ and AF: $26.9 \pm 13.9$ ) in men and $37.3 \pm 24.2 \mathrm{~g} / \mathrm{d}$ (NF: $18.6 \pm 10.5$ and AF: $19 \pm$ 13.7) in women; these intakes were approximately 8 and 7 percent of the total energy intakes, in men and women respectively. Characteristics of the study participants across quartiles of total fructose intakes are presented in Table 1. Participants in the highest quartile of fructose intakes were significantly older as compared with participants in the lowest quartile. Also, means of body mass index and the prevalence of metabolic syndrome were significantly increased across quartiles of dietary intakes of fructose in both sexes. No significant difference in smoking status and physical activity was observed across quartiles of fructose intakes. Age-adjusted means for dietary intakes across categories of dietary fructose are shown in Table 2. Dietary intakes of carbohydrate (\% of $\mathrm{kcal}$ ), total sugar (\% of kcal), natural and added fructose (\% of $\mathrm{kcal}$ ) and total dietary fiber $(\mathrm{g} / \mathrm{d}$ ) were significantly increased across quartile of total dietary fructose, whereas dietary fat intakes (\% of kcal) were significantly decreased in both sexes. Mean intake of total dietary fructose in the $4^{\text {th }}$ quartile was 2.8 and 3.7 times higher as compared to the first quartile in men and women, respectively. The means of metabolic syndrome features across quartile of fructose intakes are provided in Figure 1. After adjustment for age, energy intake, physical activity and smoking status, the mean of waist circumference across quartiles of fructose intakes were significantly increased $(P$ trend $=0.03$ and 0.007 , in men and women, respectively). Also, dietary fructose intakes in men were positively associated with systolic $(P$ trend $=0.02)$ and diastolic blood pressure ( $P$ trend $=0.013)$; in women, this association was observed only for systolic blood pressure $(P$ trend $=0.04)$. There were no significant differences in serum fasting glucose, triglycerides and HDL-C across dietary fructose categories in men and women. The association between total dietary fructose and MetS components is presented in Table 3. Total dietary fructose independently correlated with waist circumference, triglycerides, fasting blood gluocse, systolic and diastolic blood pressure, in both men and women. Compared with those in the lowest quartile of fructose intakes, men and women in the highest quartile, respectively, had 33\% (95\% CI, 1.15-1.47) and 20\% (95\% CI, 1.09-1.27) higher risk of the metabolic syndrome, after adjustment for potential confounding variables (Figure 2). Also, men and women in the highest quartile of fructose intakes, respectively, had 39 and $20 \%$ higher risk for large waist circumference, 11 and 9\% higher risk for hypertension, and both a $9 \%$ higher risk of impaired fasting glucose.

\section{Discussion}

In this study, the higher intake of dietary fructose was associated with the higher risk of MetS in adults, independent of confounding variables. It should be noted that, in our study the association between dietary fructose and metabolic syndrome and its components was observed only in the third and fourth quartiles of fructose intakes, approximately over 8 and $12 \%$ of energy intake (> $50 \mathrm{~g} / \mathrm{d}$ ); while dietary intake of fructose from natural sources including fruits and vegetables, even in the fourth quartile of fructose intakes was only $5 \%$ of energy, approximately $30 \mathrm{~g} / \mathrm{d}$. Thus, the increased risk of metabolic syndrome 
Table 1 Characteristics of adult participants across quartiles of total dietary intake of fructose: Tehran Lipid and Glucose Study ${ }^{1}$

\begin{tabular}{|c|c|c|c|c|c|c|c|c|c|c|}
\hline & \multicolumn{5}{|c|}{ Men $(n=1141)$} & \multicolumn{5}{|c|}{ Women $(n=1396)$} \\
\hline & Q1 & Q2 & Q3 & Q4 & $P^{1}$ & Q1 & Q2 & Q3 & Q4 & $p$ \\
\hline $\begin{array}{l}\text { Dietary fructose range } \\
(\mathrm{g} / 1000 \mathrm{kcal} / \mathrm{d})\end{array}$ & $\leq 13.3$ & $13.3-17.5$ & $17.6-23.7$ & $>23.7$ & & $\leq 10.3$ & $10.4-15.2$ & $15.3-20.8$ & $>20.8$ & \\
\hline $\begin{array}{l}\text { Dietary fructose median } \\
(\mathrm{g} / 1000 \mathrm{kcal} / \mathrm{d})\end{array}$ & 11.1 & 15.4 & 19.7 & 28.1 & & 7.2 & 12.6 & 17.9 & 25.9 & \\
\hline Participants (n) & 285 & 284 & 285 & 287 & & 338 & 359 & 349 & 350 & \\
\hline Age (y) & $38 \pm 12^{2}$ & $39 \pm 13$ & $41 \pm 13$ & $43 \pm 13$ & $<0.01$ & $37 \pm 12$ & $37 \pm 12$ & $39 \pm 13$ & $41 \pm 13$ & $<0.01$ \\
\hline Physical activity (MET-h/wk) & $40.5 \pm 69.2^{2}$ & $43.4 \pm 74.2$ & $45.3 \pm 72.8$ & $36.8 \pm 62.4$ & NS & $29.9 \pm 37.9$ & $32.2 \pm 41.5$ & $32.3 \pm 55.5$ & $32 \pm 37.9$ & NS \\
\hline Body mass index $\left(\mathrm{kg} / \mathrm{m}^{2}\right)$ & $26.1 \pm 0.2^{3}$ & $26.3 \pm 0.2$ & $26.9 \pm 0.2$ & $27.3 \pm 0.2$ & $<0.01$ & $26.2 \pm 0.2$ & $26.8 \pm 0.2$ & $27.7 \pm 0.2$ & $27.8 \pm 0.2$ & $<0.05$ \\
\hline Waist/hip ratio & $0.94 \pm 0.07^{3}$ & $0.94 \pm 0.06$ & $0.95 \pm 0.06$ & $0.96 \pm 0.05$ & $<0.01$ & $0.81 \pm 0.08$ & $0.82 \pm 0.09$ & $0.82 \pm 0.08$ & $0.84 \pm 0.09$ & $<0.05$ \\
\hline Total cholesterol (mmol/l) & $4.83 \pm 0.06^{3}$ & $4.71 \pm 0.06$ & $4.78 \pm 0.06$ & $4.81 \pm 0.06$ & NS & $4.71 \pm 0.05$ & $4.73 \pm 0.05$ & $4.81 \pm 0.05$ & $4.88 \pm 0.05$ & $<0.05$ \\
\hline LDL-cholesterol (mmol/l) & $3.05 \pm 0.05^{3}$ & $2.92 \pm 0.05$ & $2.95 \pm 0.05$ & $2.99 \pm 0.05$ & NS & $2.87 \pm 0.04$ & $2.89 \pm 0.04$ & $2.97 \pm 0.04$ & $2.84 \pm 0.04$ & NS \\
\hline Current smoker (\%) & 24.6 & 25 & 23.5 & 23.7 & NS & 3.0 & 2.2 & 2.9 & 3.4 & NS \\
\hline Abdominal obesity (\%) & 48.4 & 47.2 & 52.3 & 58.5 & $<0.05$ & 18.6 & 25.3 & 27.8 & 27.4 & $<0.01$ \\
\hline Impaired fasting glucose (\%) & 12.6 & 15.1 & 15.4 & 18.1 & NS & 10.1 & 13.9 & 15.8 & 14.0 & NS \\
\hline Hypertriglyceridemia (\%) & 44.6 & 41.2 & 44.9 & 46.3 & NS & 27.5 & 25.6 & 28.9 & 34.6 & $<0.05$ \\
\hline Low HDL-cholesterol (\%) & 58.6 & 63.3 & 57.2 & 64.8 & NS & 69.2 & 69.6 & 69.1 & 69.7 & NS \\
\hline Hypertension (\%) & 21.1 & 23.6 & 30.2 & 32.1 & $<0.01$ & 12.1 & 17.3 & 14.6 & 19.1 & NS \\
\hline Metabolic syndrome (\%) & 31.9 & 34.9 & 37.2 & 44.3 & $<0.01$ & 16.3 & 20.9 & 21.8 & 27.1 & $<0.01$ \\
\hline
\end{tabular}

${ }^{1} P$ values comparing the characteristics of participants across quartiles of fructose intake using analysis of variance (for age and physical activity), general linear model (for body mass index, waist/hip ratio, total and LDL-cholesterol), and Chi-square test for categorized variables.

${ }^{2}$ Values are mean \pm SD

${ }^{3}$ Values are age-adjusted mean \pm SEM

and its components may be attributed to increase fructose intake from industrialized foods.

To our knowledge, this is the first study to directly relate dietary fructose intake with the MetS, based on a large population, cross-sectional setting. Johnson and colleagues, in a recent review of animal studies and human clinical trials, proposed that excessive fructose intake, $>50 \mathrm{~g} / \mathrm{d}$ may be one of the main etiologies of

Table 2 Dietary intakes of adult participants by quartiles of total fructose intake: Tehran Lipid and Glucose Study

\begin{tabular}{|c|c|c|c|c|c|c|c|c|c|c|}
\hline & \multicolumn{5}{|c|}{ Males $(n=1141)$} & \multicolumn{5}{|c|}{ Females $(n=1396)$} \\
\hline & Q1 & Q2 & Q3 & Q4 & $P^{2}$ & Q1 & Q2 & Q3 & Q4 & $p$ \\
\hline Energy intake (kcal/d) & $2357 \pm 41^{1}$ & $2538 \pm 41$ & $2444 \pm 41$ & $2375 \pm 41$ & $<0.05$ & $2191 \pm 35$ & $2241 \pm 34$ & $2237 \pm 34$ & $2223 \pm 34$ & NS \\
\hline $\begin{array}{l}\text { Carbohydrate (\% of } \\
\text { energy) }\end{array}$ & $56.7 \pm 0.4$ & $58.1 \pm 0.4$ & $58.8 \pm 0.4$ & $62.4 \pm 0.4$ & $<0.05$ & $53.4 \pm 0.3$ & $54.9 \pm 0.3$ & $56.9 \pm 0.3$ & $60.6 \pm 0.3$ & $<0.05$ \\
\hline Protein (\% of energy) & $13.6 \pm 0.1$ & $13.6 \pm 0.1$ & $13.9 \pm 0.1$ & $13.8 \pm 0.1$ & NS & $13.2 \pm 0.1$ & $13.8 \pm 0.1$ & $13.7 \pm 0.1$ & $13.7 \pm 0.1$ & NS \\
\hline Fat (\% of energy) & $31.1 \pm 0.4$ & $30 \pm 0.4$ & $29.9 \pm 0.4$ & $27.4 \pm 0.4$ & $<0.001$ & $34.9 \pm 0.4$ & $33.6 \pm 0.4$ & $32.3 \pm 0.4$ & $29.7 \pm 0.4$ & $<0.001$ \\
\hline $\begin{array}{l}\text { Simple carbohydrate } \\
\text { (\% of energy) }\end{array}$ & $18.9 \pm 0.3$ & $21.4 \pm 0.3$ & $24.1 \pm 0.3$ & $28.6 \pm 0.3$ & $<0.001$ & $18.5 \pm 0.2$ & $21.5 \pm 0.2$ & $23.7 \pm 0.2$ & $28.7 \pm 0.2$ & $<0.001$ \\
\hline Fiber (g/1000 kcal/d) & $14.5 \pm 0.4$ & $17.3 \pm 0.4$ & $17.4 \pm 0.4$ & $18.2 \pm 0.4$ & $<0.001$ & $14.7 \pm 0.3$ & $15.5 \pm 0.3$ & $17.3 \pm 0.3$ & $18.6 \pm 0.3$ & $<0.001$ \\
\hline $\begin{array}{l}\text { Natural fructose }{ }^{4} \text { (\% } \\
\text { of energy) }\end{array}$ & $1.7 \pm 0.04$ & $2.6 \pm 0.04$ & $3.4 \pm 0.04$ & $5.2 \pm 0.04$ & $<0.001$ & $1.7 \pm 0.03$ & $2.6 \pm 0.03$ & $3.6 \pm 0.03$ & $5.4 \pm 0.03$ & $<0.001$ \\
\hline $\begin{array}{l}\text { Added fructose } 5 \text { ( } \% \text { of } \\
\text { energy) }\end{array}$ & $2.5 \pm 0.05$ & $3.6 \pm 0.05$ & $4.6 \pm 0.05$ & $7.0 \pm 0.05$ & $<0.001$ & $1.2 \pm 0.05$ & $2.3 \pm 0.05$ & $3.6 \pm 0.05$ & $5.9 \pm 0.03$ & $<0.001$ \\
\hline \multicolumn{11}{|l|}{ Total dietary fructose } \\
\hline (\% of energy) & $4.3 \pm 0.09$ & $6.2 \pm 0.09$ & $8.0 \pm 0.09$ & $12.2 \pm 0.09$ & $<0.001$ & $2.9 \pm 0.09$ & $5.0 \pm 0.09$ & $7.2 \pm 0.09$ & $11.3 \pm 0.09$ & $<0.001$ \\
\hline (\% of carbohydrate) & $7.7 \pm 0.15$ & $10.7 \pm 0.15$ & $13.8 \pm 0.15$ & $19.6 \pm 0.15$ & $<0.001$ & $5.6 \pm 0.14$ & $9.3 \pm 0.14$ & $12.8 \pm 0.14$ & $18.7 \pm 0.14$ & $<0.001$ \\
\hline (g/d) & $26.4 \pm 0.7$ & $37 \pm 0.7$ & $48.7 \pm 0.7$ & $73.6 \pm 0.7$ & $<0.001$ & $17.0 \pm 0.6$ & $28.2 \pm 0.6$ & $40.4 \pm 0.6$ & $63.3 \pm 0.6$ & $<0.001$ \\
\hline
\end{tabular}

1 Data are age-adjusted mean \pm SEM

${ }^{2} P$ values comparing dietary intake of participants across quartiles of fructose intake using linear regression model.

${ }^{3}$ Dietary Simple carbohydrates includes sucrose, maltose, galactose, glucose, fructose, maltose.

${ }^{4}$ Natural fructose in fructose-containing food such as fruits, vegetables, honey, etc.

${ }^{5}$ Fructose content of industrialized foods and beverages containing beet or cane sugar/molasses, corn sweeteners and invert syrup 


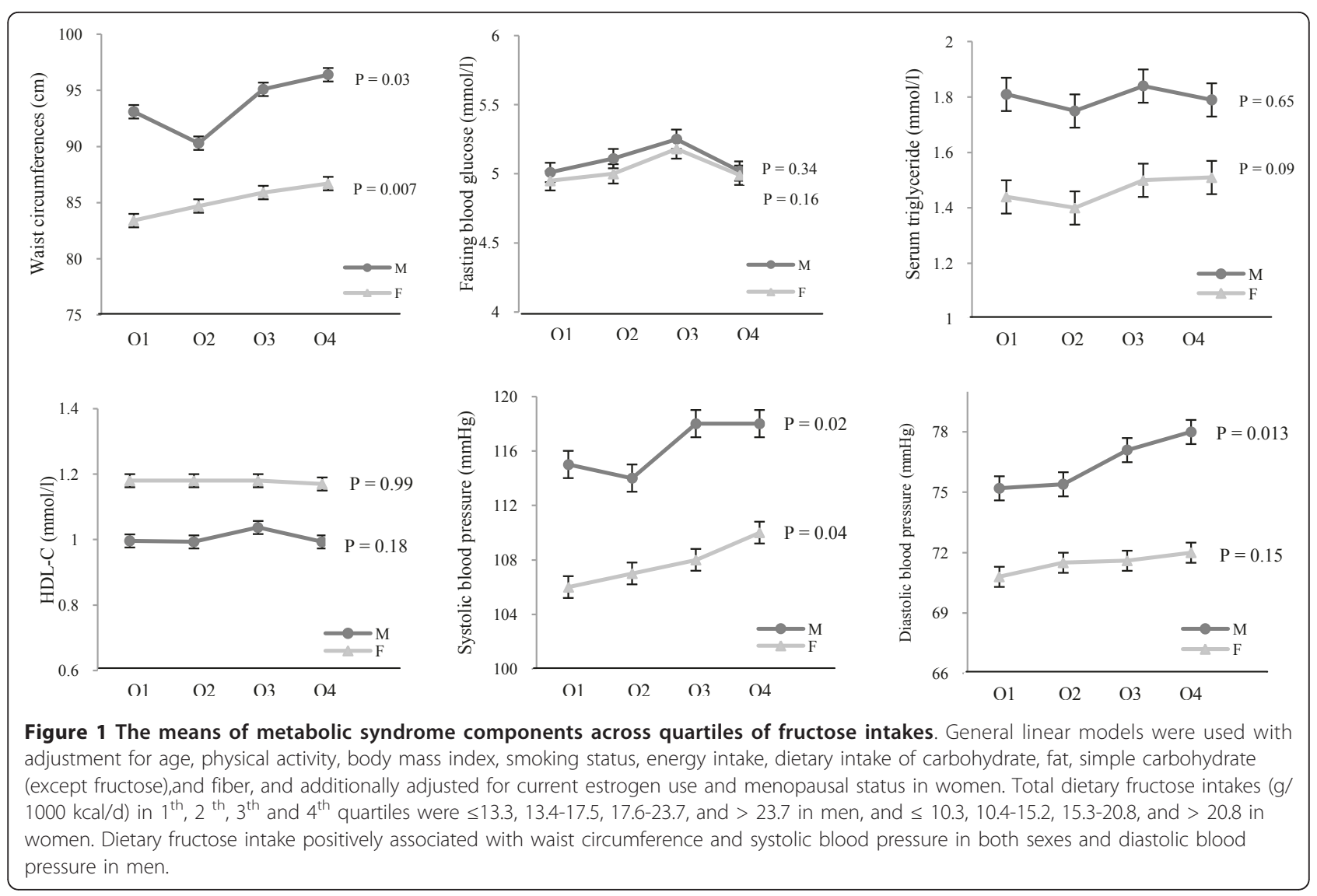

the metabolic syndrome [27]. In the current study, mean intake of total fructose in men and women, was $\approx 8 \%$ and $\approx 7 \%$ of average energy intake. Dietary fructose from fruit, vegetable and other natural sources, was approximately, 40 and $60 \%$ of total fructose in men and women, respectively, while the rest was from beet and cane sugars, soft drink, fruit drink, cookies, candies, jams and bakery products. A recent report from the third National Health Examination Survey (NHANES) demonstrated that over $10 \%$ of energy intakes in US adults were from fructose [28].

In this study, dietary fructose intakes $>12 \%$ from energy were related to higher chances of having abdominal obesity, and increasing fructose intakes were associated with an increase in body mass index. Findings in line with the results of studies in rats indicating that high fructose diet increased lipogenesis, fat storage, and leptin resistance [29-31]. Administration of 25\% fructose diet in overweight and obese subjects for 10 weeks increased intra-abdominal fat storage [7]. Compared with other carbohydrates, mechanisms by which fructose may cause weight gain could be that, fructose increases hunger rating and energy intake, does not stimulate insulin and postprandial leptin levels and inhibits secretion of orexigenic hormone ghrelin, as satiety signals to the brain [32]. Fructose also up regulates de novo lipogenesis in human [7]. The results from epidemiological studies are inconsistent; in a prospective study, consumption of $\geq 1$ soft drink per day was associated with increased risk of developing obesity and waist circumference [33]. In another study, this correlation was not found among preschool children [34].

Table 3 Multivariate association between total dietary fructose intake and metabolic syndrome components: Tehran Lipid and Glucose Study

\begin{tabular}{lcccccc}
\hline & WC & TG & FBS & HDL-C & SBP & DBP \\
\hline Men & $0.158(0.001)$ & $0.076(0.08)$ & $0.115(0.007)$ & $-0.066(0.12)$ & $0.103(0.016)$ & $0.167(0.001)$ \\
Women & $0.155(0.001)$ & $0.130(0.001)$ & $0.135(0.001)$ & $-0.012(0.76)$ & $0.164(0.001)$ & $0.115(0.006)$ \\
\hline
\end{tabular}

Values are standardized coefficient $\beta$ ( $P$ value) were determined using the linear regression model with adjustment for age, physical activity, body mass index (except for waist circumference and metabolic syndrome), smoking status, energy intake, dietary intake of carbohydrate, fat, simple sugar (except fructose), and fiber. WC; Waist circumference, TG; Triglycerides, FBS; Fasting blood glucose, HDL-C; High density lipoprotein, SBP; Systolic blood pressure, DBP; Diastolic blood pressure. 

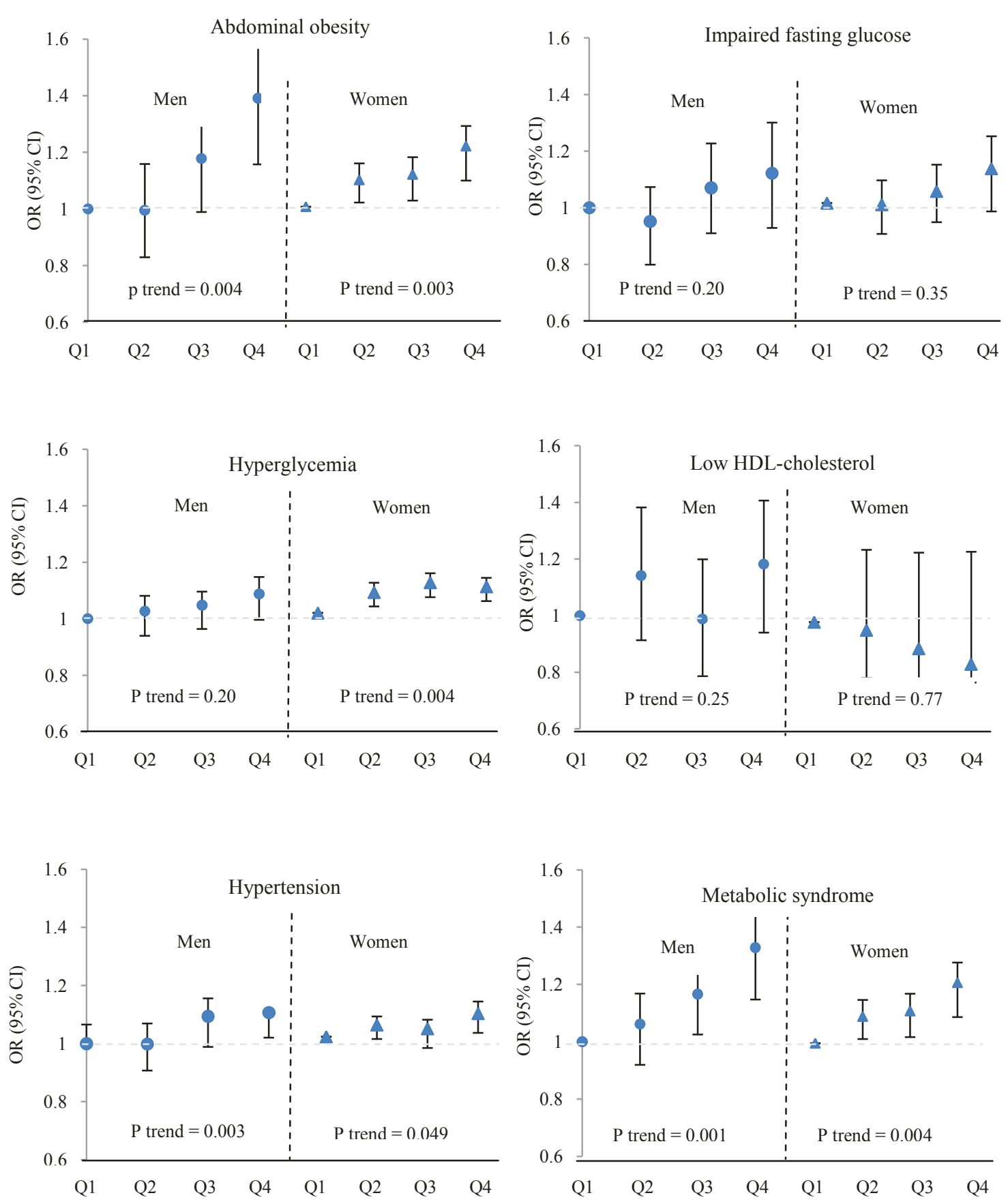

Figure 2 Multivariate odds ratio and 95\% confidence interval for the metabolic syndrome and its components across quartiles of fructose intake. Logistic regression models were used with adjustment for age, physical activity, body mass index, smoking status, energy intake, dietary intake of carbohydrate, fat, simple carbohydrate (except fructose), fiber, and additionally adjusted for current estrogen use and menopausal status in women. Total dietary fructose intakes $(\mathrm{g} / 1000 \mathrm{kcal} / \mathrm{d})$ in $1^{\text {th }}, 2^{\text {th }}, 3^{\text {th }}$ and $4^{\text {th }}$ quartiles were $\leq 13.3,13.4-17.5,17.6-23.7$, and $>23.7$ in men, and $\leq 10.3,10.4-15.2,15.3-20.8$, and $>20.8$ in women. To assess the overall trends of odds ratios across increasing quartiles of total fructose intake, the median fructose intake of each quartile was used as a continuous variable in logistic regression models.

In this study, participants with the highest intakes of fructose had higher risk of impaired fasting glucose. Although fructose does not stimulate insulin secretion, it induced impaired fasting glucose by insulin resistance in the liver and adipose tissue [35,36]. In humans, high doses of fructose decreased insulin sensitivity and glucose tolerance in older, overweight and obese subjects, whereas lower doses did not in young, normal weight 
men; however fructose caused a 5.5\% increase in fasting glucose concentration in these subjects [7,37]. A large cross-sectional study showed that the highest quintile of fructose intake had $13.9 \%$ higher C-peptide levels, as a risk factor for insulin resistance [38].

In the present study, fructose intakes $>72$ and $63 \mathrm{~g} / \mathrm{d}$ in men and women were associated with 11 and 9\% increased risk of hypertension, respectively. In one study, administration of $200 \mathrm{~g} / \mathrm{d}$ fructose in healthy adults significantly increased systolic and diastolic blood pressure [39]. In the Framingham Heart Study, consumption of soft drinks increased risk of hypertension [33]. Furthermore, recent data from a cross-sectional study demonstrated that high fructose intake in the form of added sugar was associated with higher blood pressure levels in adults [40]. Some studies proposed that hypertension-induced effects of fructose may be related to the ability of fructose to increase serum uric acid and enhance reabsorption of salt and water in the small intestine and kidney [41,42]. However in a recent cross-sectional study, no association was found between dietary fructose and risk of hyperuricemia in adults [21]. Also, blood pressure did not change with the high consumption of fructose over the course of the 10 week intervention period [7].

The current study showed that there were no significant associations between fructose intake and fasting serum triglycerides, and HDL-cholesterol. Excessive fructose intake for 2 weeks in healthy subjects resulted in hypertriglyceridemia and decreased HDL-cholesterol levels ${ }^{(39)}$. Stanhope et al showed that administration of a diet with $25 \%$ fructose for 10 weeks did not change fasting TG concentrations, but increased postprandial de novo lipogenesis and TG concentrations, fasting and postprandial apo B and LDL-C concentrations in overweight and obese subjects [7]. However results from a recent meta-analysis, suggested that dietary fructose intakes less than $50 \mathrm{~g} / \mathrm{d}$ had no adverse effect on fasting and postprandial triglycerides [43]. Although, in an observational study of overweight children, no association was observed between fructose consumption and HDL, LDL, total cholesterol and triglyceride concentrations, fructose intake was a significant predictor of LDL particle size as an atherogenic risk factor [44]. More observational studies need to be conducted on the association between usual intakes of fructose and lipid profiles among adults.

One limitation of this study is the use of an FFQ for collecting dietary data. Also total fructose intake was estimated approximately, because of a lack of fructose content data for many food items. In addition, this is a cross sectional study which limits ability to determine causality between dietary fructose intake, MetS and its components.
In conclusion, in this study, higher dietary fructose intake was significantly associated with the increased risk of metabolic syndrome and some of its risk factors including abdominal obesity, hypertension and impaired fasting glucose in adults, even after adjustment for demographic, anthropometric and dietary intakes.

\section{Acknowledgements}

We thank the TLGS participants and the field investigators of the TLGS for their assistance in physical examinations, biochemical and nutritional evaluation and database management. This study was supported by grant 121 from National Research Council of the Islamic Republic of Iran and Research Institute for Endocrine Sciences of Shahid Beheshti University of Medical Sciences. We would like to thank Ms N.Shiva for language editing of the manuscript.

\section{Author details}

${ }^{1}$ Obesity Research Center, Research Institute for Endocrine Sciences, Shahid Beheshti University of Medical Sciences. No 24 Parvaneh St, Yemen St, Chamran Exp, Tehran, 19395-4763, Iran. ${ }^{2}$ Department of Clinical Nutrition and Dietetics, Faculty of Nutrition Sciences and Food Technology, National Nutrition and Food Technology Research Institute, Shahid Beheshti University of Medical Sciences. No 46 Arghavan-e-gharbi St, Farahzadi Blv, Shahrak-e-Ghods. Tehran, 19395-4741, Iran. ${ }^{3}$ Endocrine Research Center, Research Institute for Endocrine Sciences, Shahid Beheshti University of Medical Sciences. No 24 Parvaneh St, Yemen St, Chamran Exp, Tehran, 19395-4763, Iran.

\section{Authors' contributions}

The project idea for this study was from FHE. The project was design by FHE, P.M and ZB. The ZB, FH and SHN analyzed and interpreted the data. ZB, $\mathrm{PM}$ and FA prepared the manuscript. All authors read and approved the final version of the manuscript to be submitted.

\section{Competing interests}

The authors declare that they have no competing interests.

Received: 13 March 2011 Accepted: 12 July 2011

Published: 12 July 2011

\section{References}

1. Miller A, Adeli K: Dietary fructose and the metabolic syndrome. Current Opinion in Gastroenterology. 2008, 24:204-209.

2. Basciano $H$, Federico $L$, Adeli K: Fructose, insulin resistance, and metabolic dyslipidemia. Nutr Metab 2005, 2(1):5.

3. Bray G: Fructose: should we worry? Int J Obes 2008, 32:S127-31.

4. Johnson RJ, Segal MS, Sautin Y, Nakagawa T, Feig DI, Kang DH, Gersch MS, Benner S, Sánchez-Lozada LG: Potential role of sugar (fructose) in the epidemic of hypertension, obesity and the metabolic syndrome, diabetes, kidney disease, and cardiovascular disease. Am J Clin Nutr 2007, 86:899-906.

5. Bray GA, Nielsen SJ, Popkin BM: Consumption of high-fructose corn syrup in beverages may play a role in the epidemic of obesity. Am J Clin Nutr 2004, 79:537-43.

6. Jürgens $H$, Haass W, Castañeda TR, Schürmann A, Koebnick C, Dombrowski F, Otto B, Nawrocki AR, Scherer PE, Spranger J, Ristow M, Joost HG, Havel PJ, Tschöp MH: Consuming fructose-sweetened beverages increases body adiposity in mice. Obes Res 2005, 13:1146-56.

7. Stanhope KL, Schwarz JM, Keim NL, Griffen SC, Bremer AA, Graham JL: Consuming fructose-sweetened, not glucose-sweetened, beverage increases visceral adiposity and lipids and decreases insulin sensitivity in overweight/obese humans. J Clin Invest 2009, 119:1322-34.

8. Rizkalla SW: Health implications of fructose consumption: A review of recent data. Nutr Metabol 2010, 7:82.

9. Ferder L, Fereder MD, Inserra F: The role of high fructose corn syrope in metabolic syndrome and hypertension. Curr Hypertens Rep 2010, 12(2):105-12.

10. Wiernsperger N, Geloen A, Rapin JR: Fructose and cardiometabolic disorders: the controversy will, and must, continue. Clinics 2010, 65:729-38. 
11. Third Report of National Cholesterol Education Program (NCEP) Expert Panel on detection, evaluation, and treatment of high blood cholesterol in adults (Adult Treatment Panel III). Circulation 2002, 106:3143-3421.

12. Azizi F, Salehi P, Etemadi A, ZahediAsl S: Prevalence of metabolic syndrome in an urban population: Tehran Lipid and Glucose Study. Diabetes Res Clin Pract 2003, 61:29-37.

13. Zabetian A, Hadaegh F, Sarbakhsh P, Azizi F: Weight change and incident metabolic syndrome in Iranian men and women: A 3-year follow-up study. BMC Public Health 2009, 9:138.

14. Azizi F, Ghanbarian A, Momenan AA, Hadaegh F, Mirmiran P, Hedayati M, Mehrabi Y, Zahedi-Asl S, Tehran Lipid and Glucose Study Group: Prevention of non-communicable disease in a population in nutrition transition: Tehran Lipid and Glucose Study phase II. Trials 2009, 10:5.

15. Azizi F, Rahmani M, Emami H, Mirmiran P, Hajipour R, Madjid M, Ghanbili J, Ghanbarian A, Mehrabi Y, Saadat N, Salehi P, Mortazavi N, Heydarian P, Sarbazi N, Allahverdian S, Saadati N, Ainy E, Moeini S: Cardiovascular risk factors in an Iranian urban population: Tehran Lipid and Glucose Study. J Sco Prev Med 2002, 47:408-26.

16. Hosseini F, Jesri M, Mirmiran P, Bastan S, Azizi F: Adherence to dietary recommendations and risk of metabolic syndrome: Tehran Lipid and Glucose Study. Metabolism 2010, 59:1833-42.

17. Mirmiran $P$, Hosseini F, Mehrabi $Y$, Hedayati M, Azizi F: Riliability and relative validity of a food frequency questionnaire for nutrients in the Tehran Lipid and Glucose Study. Public Health Nutr 2010, 13:654-62.

18. The Nutrient Data Laboratory. Food Composition Table (FCT), food and nutrition information center, United State Department of Agriculture (USDA). [http://www.nal.usda.gov/fnic/foodcomp].

19. Azar M, Sarkisian E: Food Composition Table of Iran. National Nutrition and Food Research Institute Shahid Beheshti University Press; 1980.

20. Database for the Added Sugars Content of Selected Foods. Food and nutrition information center, United State Department of Agriculture (USDA) [http://www.ars.usda.gov/Services/docs.htm?docid=12107 ].

21. Sun sz, Flickinger BD, Williamson PS, Empie MW: Lack of association between dietary fructose and hyperuricemia risk in adults. Nut Metabol 2010, 7:16.

22. Grundy SM, Cleeman JI, Daniels SR, Donato KA, Eckel RH, Franklin BA, Gordon DJ, Krauss RM, Savage PJ, Smith SC Jr, Spertus JA, Costa F, American Heart Association; National Heart and Blood Institute: Diagnosis and management of the metabolic syndrome: an American Heart Association/National Heart, Lung, and Blood Institute scientific statement. Circulation 2005, 112:2735-52.

23. Azizi F, Hadaegh F, Khalili D, Esteghamati A, Hosseinpanah F, Delavari A, Larijani B, Mirmiran P, Zabetian A, Mehrabi Y, Kelishadi R, Aghajani H: Appropriate Definition of Metabolic Syndrome among Iranian Adults: Report of the Iranian National Committee of Obesity. Archives of Iranian Medicine 2010, 13:426-8.

24. Lee J, Chia KS: Estimation of prevalence rate ratios for cross-sectional data: an example in occupational epidemiology. Br J Ind Med 1993, 50:861-2.

25. Zhang J, Yu KF: What's the relative risk? A method of correcting the odds ratio in cohort studies of common outcomes. JAMA 1998, 280:1690-1.

26. McKeown NM, Meigs JB, Liu S, Saltzman E, Wilson PW, Jacques PF: Carbohydrate nutrition, insulin resistance, and the prevalence of the metabolic syndrome in the Framingham Offspring Cohort. Diabetes Care 2004, 27:538-46

27. Johnson RJ, Perez-Pozo SE, Sautin YY, Manitius J, Sanchez-Lozada LG, Feig DI, Shafiu M, Segal M, Glassock RJ, Shimada M, Roncal C, Nakagawa T: Hypothesis: could excessive fructose intake and uric acid cause type 2 diabetes? Endocr Rev 2009, 30:96-116.

28. Vos M, Kimmons J, Gillespie C, Welsh J, Blank H: Dietary fructose consumption among US children and adults: the third National Health and Nutrition Examination Survey. Medscape J Med 2008, 10:160.

29. Nakagawa T, Hu H, Zharikov S, Tuttle KR, Short RA, Glushakova O, Ouyang X, Feig DI, Block ER, Herrera-Acosta J, Patel JM, Johnson RJ: A causal role for uric acid in fructose-induced metabolic syndrome. Am J Physiol Renal Physiol 2006, 290:F625-31.

30. Baret G, Peyronnet J, Grassi-Kassisse D, Dalmaz Y, Wiernsperger N, Geloen A: Increased intraabdominal adipose tissue mass in fructose fed rats: correction by metformin. Exp Clin Endocrinol Diabetes 2002, 110:298-303.
31. Shapiro A, Mu W, Roncal CA, Cheng KY, Johnson RJ, Scarpace PJ: Fructoseinduced leptin resistance exacerbates weight gain in response to subsequent high fat feeding. Am J Physiol Regul Integr Comp Physiol 2008, 295:R1370-5.

32. Teff KL, Elliott SS, Tschöp M, Kieffer TJ, Rader D, Heiman M, Townsend RR, Keim NL, D'Alessio D, Havel PJ: Dietary fructose reduces circulating insulin and leptin, attenuates postprandial suppression of ghrelin, and increases triglycerides in women. J Clin Endocrinol Metab 2004, 89:2963-72.

33. Dhingra R, Sullivan L, Jacques PF, Wang TJ, Fox CS, Meigs JB, D'Agostino RB, Gaziano JM, Vasan RS: Soft drink consumption and risk of developing cardiometabolic risk factors and the metabolic syndrome in middleaged adults in the community. Circulation 2007, , 116: 480-8.

34. Newby PK, Peterson KE, Berkey CS, Leppert J, Willet WC, Colditz GA: Beverage consumption is not associated with changes in weight and body mass index among low income preschool children in North Dakota. J Am Diet Assoc 2004, 104:1068-94.

35. Curry DL: Effects of mannose and fructose on the synthesis and secretion of insulin. Pancreas 1989, 4:2-9.

36. Faeh D, Minehira K, Schwarz JM, Preiasamy R, Park S, Tappy L: Effects of fructose overfeeding and fish oil administration on hepatic de novo lipogenesis and insulin ensitivity in healthy men. Diabetes 2005, 54:1907-13.

37. Lê KA, Faeh D, Stettler R, Ith M, Kreis R, Vermathen P, Boesch C, Ravussin E, Tappy L: A 4-wk high-fructose diet alters lipid metabolism without affecting insulin sensitivity or ectopic lipids in healthy humans. Am J Clin Nutr 2006, 84:1374-9.

38. Wu T, Giovannucci E, Pischon T, Hankinson SE, Ma J, Rifai N, Rimm EB: Fructose, glycemic load and quantity and quality of carbohydrate in relation to plasma C-peptide concentration in US women. Am I Clin Nutr 2004, 80:1043-9.

39. Prezo-pozo SE, Schold J, Nakagava T, Sanchezo LG, Johnson RJ, Lillo JL: Excessive fructose intake induces the features of metabolic syndrome in healthy adult men: role of uric acid in the hypertensive response. Int $J$ Obes 2010, 34:454-61.

40. Jalal DI, Smits G, Johnson RJ, Chonchol M: Increased fructose associates with elevated blood pressure. J Am Soc Nephrol 2010, 21:1543-9.

41. Madero M, Prezo-pozo SE, Jalal D, Johnson RJ, Sancheza-lozada LG: Dietary fructose and hypertension. Curr Hypertens Rep 2011, 13:29-35.

42. Soleimani M: Dietary fructose, salt absorption and hypertension in metabolic syndrome: toward a new paradigm. Acta Physiol 2010, 201:55-62.

43. Livesey G, Taylor R: Fructose consumption and consequences for glycation, plasma triacylglycerol, and body weight: meta-analyses and meta-regression models of intervention studies. Am J Clin Nutr 2008, 88:1419-37.

44. Aeberli I, Zimmermann MB, Molinari L, Lehmann R, I'Allemand D, Spinas GA, Berneis $K$ : Fructose intake is a predictor of $L D L$ particle size in overweight schoolchildren. Am J Clin Nutr 2007, 86:1174-8.

doi:10.1186/1743-7075-8-50

Cite this article as: Hosseini-Esfahani et al:: Dietary fructose and risk of metabolic syndrome in adults: Tehran Lipid and Glucose study. Nutrition \& Metabolism 2011 8:50.

\section{Submit your next manuscript to BioMed Central and take full advantage of:}

- Convenient online submission

- Thorough peer review

- No space constraints or color figure charges

- Immediate publication on acceptance

- Inclusion in PubMed, CAS, Scopus and Google Scholar

- Research which is freely available for redistribution

Submit your manuscript at www.biomedcentral.com/submit
C Biomed Central 